\title{
Axillary dissection compared to sentinel node biopsy for the treatment of pathologically node-negative breast cancer: a meta-analysis of four randomized trials with long-term follow up
}

\author{
Fausto Petrelli, Veronica Lonati, Sandro Barni \\ Azienda Ospedaliera di Treviglio, Italy
}

\begin{abstract}
Sentinel lymph node biopsy is now accepted as the initial approach for women with early stage breast cancer with clinically node-negative disease. We performed a pooled analysis of trials comparing axillary lymph node dissection to sentinel lymph node biopsy in patients with early stage breast cancer and pathologically negative sentinel lymph node analysis. A systematic MEDLINE review identified four randomized trials of axillary dissection versus sentinel lymph node biopsy in lymph node-negative early stage breast cancer patients. A meta-analysis was performed for survival and relapse. The combined analyses of these four trials found no significant difference in overall survival (relative risk $[\mathrm{RR}] 1.15 ; \mathrm{P}=0.16$; 95\% CI: 0.95-1.39), breast cancer-specific (RR 1.03; $\mathrm{P}=0.85 ; 95 \%$ CI: 0.75 1.43 ) and disease-free survival (RR 1.07; $\mathrm{P}=0.3 ; 95 \% \mathrm{CI}$ : 0.94-1.21), distant metastases (RR 1; P=0.98; 95\% CI: 0.76-1.32), and ipsilateral breast recurrence (RR $1.64 ; \mathrm{P}=0.34 ; 95 \% \mathrm{CI}$ : 0.60-4.47) associated with sentinel lymph node biopsy. In particular, a similar rate of nodal recurrences was seen after sentinel lymph node biopsy (RR $1.74 ; \mathrm{P}=0.13$; $95 \%$ CI: 0.86 3.53). Axillary dissection does not confer a survival benefit nor prevent further nodal relapses in the setting of early stage, pathologically lymph node-negative breast cancer.
\end{abstract}

\footnotetext{
Correspondence: Fausto Petrelli, Medical and Surgical Oncology Department, Medical Oncology Unit, Azienda 0spedaliera TreviglioCaravaggio; Piazzale Ospedale 1, 24047 Treviglio (BG), Italy.

Tel: +390363424420 - Fax: +39 0363424380. E-mail: faupe@libero.it

Key words: breast cancer, node negative, axillary dissection, sentinel lymph node biopsy, survival, relapse rate.
}

Contributions: the authors contributed equally.

Conflict of interests: the authors declare no potential conflict of interests.

Received for publication: 9 June 2012.

Revision received: 9 June 2012

Accepted for publication: 5 July 2012.

This work is licensed under a Creative Commons Attribution NonCommercial 3.0 License (CC BY-NC 3.0).

CCopyright F. Petrelli et al., 2012

Licensee PAGEPress, Italy

Oncology Reviews 2012; 6:e20

doi:10.4081/oncol.2012.e20

\section{Introduction}

Status of the regional lymph nodes is one of the most important prognostic factors in early stage breast cancer. The lymphatic drainage pathways of the breast (axillary, internal mammary and supraclavicular nodal groups) are the regional areas most likely to be involved with metastatic breast cancer. The axillary lymph nodes receive $85 \%$ of the lymphatic drainage from all quadrants of the breast; the remainder drains to the internal mammary chain. The likelihood of involvement is related to tumor size and location, histological grade and the presence of lymphatic invasion. ${ }^{1,2}$ In patients with clinically node-negative breast cancer, sentinel lymph node biopsy identifies patients without axillary lymph node involvement, thereby making more extensive surgery unnecessary. Axillary lymph node dissection has traditionally been a routine procedure in the staging and management of breast cancer. ${ }^{3}$ However, sentinel lymph node biopsy is now the accepted initial approach for women with early stage breast cancer, and full axillary lymph node dissection is not necessary for staging purposes in clinically node-negative patients.

An old meta-analysis of six trials that included over 3000 women who were randomly assigned to axillary lymph node dissection or no axillary lymph node dissection demonstrated an average improvement in absolute survival of $4.5 \%$ at ten years with axillary lymph node dissection, (range 4-16\%). ${ }^{4}$ However, this analysis had several limitations: the trials were conducted over a span of four decades (1951 to 1987), few patients with Tla tumors were enrolled, none of the trials used modern systemic adjuvant chemotherapy, and none enrolled women over the age of 70 years. A subsequent meta-analysis of three randomized trials comparing axillary dissection versus no dissection published between 2000 and 2007, as well as a fourth trial comparing axillary radiotherapy (RT) versus no axillary therapy, found no difference in overall survival, metastases or ipsilateral breast recurrence associated with axillary treatment. ${ }^{5}$ This may be due to the widespread use of adjuvant chemotherapy and RT during this time frame, especially since breast radiation for breast conservation includes at least the low axillary field. Axillary RT may be a reasonable alternative to axillary lymph node dissection for clinically node-negative patients in whom pathological nodal status would not alter the therapeutic plan. In fact, another study ${ }^{6}$ showed that the addition of axillary RT to total mastectomy compared to total mastectomy alone or radical mastectomy resulted in similar survival and similar nodal failure with respect to axillary surgery in node-negative patients.

Axillary lymph node dissection is now considered the standard of care for all patients diagnosed with early invasive breast cancer. However, axillary lymph node dissection carries a high rate of surgical morbidity. Lymphoedema is common and is generally the major concern for patients submitted to this procedure. Other complications could include seroma formation, shoulder dysfunction, loss of sensa- 
tion in the distribution of the intercostobrachial nerve, and mild edema of the arm and breast. Sentinel lymph node biopsy is a minimally invasive procedure designed to stage the axilla in breast cancer patients who have clinically negative nodes. According to the American College of Breast Surgeons (ACBS), sentinel lymph node biopsy is suitable for virtually all clinically node-negative T1-2 invasive breast cancer. ${ }^{7}$ The aim of this pooled analysis was to review contemporary randomized trials of axillary dissection versus sentinel lymph node biopsy to assess whether there is any survival or disease control benefit to be obtained from complete axillary lymph node clearance in the setting of early stage breast cancers and negative sentinel lymph node status.

\section{Methods of research}

\section{Selection of studies}

We conducted an independent review of Medline and EMBASE citations with no date restriction. The key words included in the search were: BREAST CANCER and AXILLARY DISSECTION and SENTINEL LYMPH NODE. The search was further limited to randomized, controlled trials in humans published in English. When duplicate publications were identified, only the most recent or most complete report of clinical trials was included. The trials that met the following criteria were chosen for the analysis: prospective, randomized clinical trials in patients with breast cancer, patients assigned to treatment with primary tumor surgery (mastectomy or breast conserving surgery) and axillary dissection or sentinel lymph node biopsy with or without breast RT. Trials were excluded if they compared axillary lymph node dissection to axillary irradiation or no axillary treatment, and if they included locally advanced breast cancer. Axillary lymph node dissection for breast cancer is generally defined as complete en bloc removal of the level I and level II lymph nodes. Studies report outcome in terms of survival or recurrence rates. No analysis of complication rates of the two procedures was carried out.

\section{Data extraction and clinical end points}

Data extraction was conducted independently by two investigators (FP and SB), and any discrepancy between the reviewers was resolved by consensus agreement. For each study, the following information was extracted: author's name, year of publication, number of enrolled subjects, treatment arms, number of patients in control and experimental groups, median follow up, median age, stage of disease, hormonal receptor status, adjuvant therapy, progression-free survival, overall survival, breast cancer-specific survival, loco regional nodal recurrences, local recurrences, and distant metastasis.

The following end points were considered and included in the analysis: death from any cause (overall survival), death without breast cancer (breast cancer-specific survival), relapse- or disease-free survival (relapse or death from any cause), or regional nodal recurrences (axillary and/or supraclavicular and/or internal mammary if mentioned separately in the text) according to the $7^{\text {th }}$ TNM classification), distant metastasis and local recurrences (chest wall or ipsilateral breast).

\section{Statistical analysis}

All statistical analyses were performed using Review Manager 5.1 software, version 5.1 (The Nordic Cochrane Centre, The Cochrane Collaboration, Copenhagen, Denmark). The number of events was extracted or calculated from the percentages reported in each publication. The proportion of patients with the above adverse outcomes and $95 \%$ confidence intervals (CI) was calculated for each arm, and the relative risk or risk ratio (RR) presented. A meta-analysis of RR was performed and both fixed-effect (weighted with inverse variance) and ran- dom-effect models were considered. The latter was calculated using the DerSimonian and Laird's method ${ }^{8}$ which considers both within- and between-study variation. The statistical heterogeneity among the studies included was assessed using Cochrane's $Q$ statistic, and the inconsistency was quantified via the $I^{2}$ statistic, which describes the percentage of total variation among studies due to heterogeneity rather than chance; a value of $0 \%$ indicates no heterogeneity, while values $0-100 \%$ show increasing heterogeneity. The assumption of homogeneity was considered invalid for $\mathrm{P}<0.1$; in this case, we reported summary estimates from random-effect models. Finally, potential publication biases were evaluated using Begg's funnel plots, and then with both Begg and Egger's tests, to examine the relative symmetry of individual study estimates around the overall estimate. A two-tailed $\mathrm{P}<0.05$ was considered statistically significant.

\section{Results}

The search retrieved 190 results, a review of which led to a total of six trials: five evaluating axillary lymph node dissection versus sentinel lymph node biopsy only if the sentinel nodes were negative on routine pathological analysis, ${ }^{9-13}$ and one evaluating axillary lymph node dissection versus sentinel lymph node biopsy if 1-2 sentinel nodes were positive only on hematoxylin and eosin staining, and the patient was a candidate for conservative surgery and post-operative RT. ${ }^{14,15}$ The ACOSOG Z0011 trial, published in 2011 with final survival data ${ }^{15}$ was excluded from the final analysis because it included only pathologically node-positive patients. At the end of the selection phase, we decided to exclude the Mansell trial ${ }^{13}$ because it was published reporting an analysis that was carried out after only a median of 12 months of follow up. A total of 5450 patients were, therefore, available for this pooled analysis. There were no significant differences in the baseline characteristics of patients (age, tumor size, histological type, tumor grade, type of surgery and adjuvant therapy) between sentinel node biopsy and dissection groups in the included trials (Table 1). Both the process of sentinel node identification (using isosulfan blue, a radiopharmaceutical, or both) and the types of breast surgery differed between studies (mastectomy or breast conservation treatment) (Table 2). The studies included were all well-designed and were of high methodological quality, with a balanced distribution of patients between groups. Median follow up ranged between 56 months and ten years.

\section{Overall survival}

All four trials reported overall survival data ( $\mathrm{n}=5424$ patients). ${ }^{9-12}$ There was no difference in overall survival between the two methods of axillary mapping (RR 1.15; $\mathrm{P}=0.16$; Figure 1 ). A risk difference of $1 \%$ was calculated $(\mathrm{P}=0.17)$.

\section{Breast cancer-specific survival}

Breast cancer-specific survival (i.e. the probability of surviving cancer in the absence of other causes of death) is a measurement parameter that is not influenced by changes in mortality due to other causes. It, therefore, provides a useful way to track survival over time according to the two different surgical treatments analyzed. All trials reported death events without breast cancer-12 for a total of $n=5424$ patients. One hundred and forty-three death events without breast cancer were recorded with no difference between arms (RR 1.03; $\mathrm{P}=0.85$; Figure 2) and there were only 3 more deaths in the sentinel lymph node biopsy arms (risk difference $<1 \% ; \mathrm{P}=0.86$ ).

\section{Disease-free survival}

No overall difference in disease-free survival was reported in the 
Table 1. Patients' characteristics from the reviewed randomized trials.

\begin{tabular}{|c|c|c|c|c|}
\hline Study [ref.] & Zavagno ${ }^{12}$ & Canavese $^{9}$ & $\operatorname{Krag}^{10}$ & Veronesill \\
\hline Control arm & ALND & ALND & ALND & ALND \\
\hline Study arm & SLNB and ALND only if +ve & SLNB and ALND only if +ve & SLNB and ALND only if +ve & SLNB and ALND only if +ve \\
\hline Enrollment & 1999-2004 & 1998-2001 & 1999-2004 & 1998-1999 \\
\hline Median follow up & 56 months & 5.5 years & 95.6 months & 10 years \\
\hline Total n. of pts (exp vs ctr arms) & 697 (345 vs 352) & 248 (124 vs 124) & 3989 (2011 vs 1978) & 516 (259 vs 257) \\
\hline Median age (exp $v s$ ctr arms) years & rs $\quad 57.6$ vs 58.2 (mean) & 60 vs 59 & 75.6 vs $75.3>50$ & 55 vs 56 \\
\hline Type of surgery (exp vs ctr arms) & $\begin{array}{c}\text { BCS (84.9 vs 84.4\%) } \\
\text { Mastectomy (14.8 vs } 14.8 \%)\end{array}$ & $\begin{array}{c}\text { All received BCS } \\
\text { except } 2 \text { of } 225 \text { assessable } \\
\text { patients received mastectomy }\end{array}$ & $\begin{array}{l}\text { BCS ( } 87.3 \text { vs } 87.7 \%) \\
\text { Mastectomy } \\
(12.7 \text { vs } 12.3 \%)\end{array}$ & BCS $100 \%$ \\
\hline T1 (exp vs ctr arms) (\%) & 80.6 vs 81.5 & 88.2 vs 74.8 & 84 vs $83.7 \%$ & $100 \%$ \\
\hline $\begin{array}{l}\text { ER and/or PgR+ } \\
\text { (exp vs ctr arms) (\%) }\end{array}$ & 83.5 vs 81.5 & 85.5 vs 82.1 & NR & 92 vs $92 \%$ \\
\hline $\begin{array}{l}\text { Hormonal therapy (\%) } \\
\text { Chemotherapy (\%) }\end{array}$ & $\begin{array}{l}\text { According to } \\
\text { standard practice }\end{array}$ & $\begin{array}{l}\text { According to } \\
\text { standard practice }\end{array}$ & $\begin{array}{l}84.2 \text { vs } 85.1 \text { received } \\
\text { systemic therapy }\end{array}$ & $\begin{array}{l}\quad 49 \text { vs } 52 \% \\
\quad 6 \text { vs } 8 \% \\
\text { (both } 41 \text { vs } 39 \%) \\
\end{array}$ \\
\hline Radiotherapy (\%) & All pts with BCS & All pts with BCS & 82 vs $81.9 \%$ & $100 \%$ \\
\hline
\end{tabular}

SLNB, sentinel lymph node biopsy; ALND, axillary lymph node dissection; Pts, patients; Exp, experimental; Ctr, control; BCS, breast conserving surgery; NR, not reported; IHC, immunohistochemical: +ve positive.

Table 2. Pre-operative work up, sentinel lymph node biopsy and axillary dissection technique, pathological examination.

\begin{tabular}{|c|c|c|c|c|}
\hline Study [ref.] & Zavagno $^{12}$ & Canavese $^{9}$ & $\operatorname{Krag}^{10}$ & Veronesill \\
\hline Preoperative work up & Not reported & Mammography and breast+ & $\begin{array}{c}\text { Not reported } \\
\text { axillary echography }\end{array}$ & Not reported \\
\hline Lymphoscintigraphy & Yes, the day before surgery & Yes, the day before surgery & Yes, the day of surgery & $\begin{array}{c}\text { Yes } \\
\text { (79\% the day before surgery) }\end{array}$ \\
\hline Type of tracer (dose) & $\begin{array}{l}\text { 99mTechnetium } \\
(30-50 \mathrm{mBq})\end{array}$ & $\begin{array}{l}99 \mathrm{mTechnetium} \\
(0.2 \mathrm{mCi})+\text { blue dye }\end{array}$ & $\begin{array}{c}99 \mathrm{mTechnetium} \\
\text { (30 min-8 h before surgery) } \\
\text { +blue dye } \\
\text { (5 min before surgery) }\end{array}$ & 99mTechnetium (5-10 mBq) \\
\hline Site of tracer injection & Peritumoral & Peritumoral & Peritumoral & Peritumoral \\
\hline $\begin{array}{l}\text { Timing of sentinel nod } \\
\text { biopsy (identification) }\end{array}$ & $\begin{array}{l}\text { de } \\
\text { At surgery with } \\
\text { intraoperative evaluation } \\
\text { ( } \gamma \text {-ray probe) }\end{array}$ & $\begin{array}{c}\text { A surgery with } \\
\text { intraoperative evaluation } \\
\text { ( } \gamma \text {-ray probe })\end{array}$ & At surgery & $\begin{array}{l}\text { At surgery with } \\
\text { intraoperative evaluation } \\
\text { with frozen sections } \\
\text { ( } \gamma \text {-ray probe })\end{array}$ \\
\hline Extent of axillary disse & ection Axillary levels I-II & Not reported & Not reported & Axillary levels I-II-III \\
\hline $\begin{array}{l}\begin{array}{l}\text { Pathological } \\
\text { examination } \\
\text { of sentinel nodes }\end{array} \\
\text { If } \\
\text { Fo } \\
\text { Cl }\end{array}$ & $\begin{array}{c}\text { For frozen section } \\
\text { examination, SLNs with diameters } \\
\text { of }<0.5 \mathrm{~cm} \text { bisected. } \\
\text { If }>0.5 \mathrm{~cm} \text {, sectioned every } 2-3 \mathrm{~mm} \text {. } \\
\text { For each sample, } \\
2 \text { frozen sections made at } 40 \mu \mathrm{m} \text {. } \\
\text { or definitive histology, } 2 \text { consecutive } \\
5 \mu \mathrm{m} \text { thick tissue sections were } \\
\text { cut from a paraffin block at } 2 \text { levels, } \\
40 \mu \mathrm{m} \text { apart from each other. }\end{array}$ & $\begin{array}{l}\text { The SLN was bisected } \\
\text { along its major axis } \\
\text { and } 5 \text { pairs of frozen sections, } \\
\text { each } 4 \mu \mathrm{m} \text { thick, } \\
\text { were cut every } 10 \mu \mathrm{m} \text { in } \\
\text { each half of the node. }\end{array}$ & $\begin{array}{l}\text { All SLNs were assessed } \\
\text { postoperatively with } \\
\text { routine stains } \\
\text { at about } 2 \mathrm{~mm} \\
\text { intervals through } \\
\text { the node. }\end{array}$ & $\begin{array}{l}\text { SN large enough to be cut, } \\
15 \text { pairs of } 4 \mu \mathrm{m} \text { thick } \\
\text { frozen sections were } \\
\text { cut at } 50 \mu \mathrm{m} \text { intervals } \\
\text { in each half lymph node } \\
\text { ( } 60 \text { sections per node). }\end{array}$ \\
\hline $\begin{array}{l}\text { Pathological } \\
\text { examination } \\
\text { of non-sentinel nodes }\end{array}$ & Standard technique & Not reported & Not reported & $\begin{array}{l}\text { Nodes }>5 \mathrm{~mm} \text { in diameter } \\
\text { were bisected; those }<5 \mathrm{~mm} \\
\text { were fixed and embedded uncut. } \\
\text { Approx. } 3-6 \text { sections were obtained } \\
\text { from each node at different } \\
\text { levels, } 100 \text { to } 500 \mu \mathrm{m} \text { apart, } \\
\text { and stained with H\&E. }\end{array}$ \\
\hline $\begin{array}{l}\text { Detection } \\
\text { of metastasis }\end{array}$ & Routine H\&E+IHC & $\begin{array}{l}\text { Routine } \mathrm{H \& E}+\mathrm{IHC} \text { only } \\
\text { if results were ambiguous }\end{array}$ & $\begin{array}{l}\text { Routine H\&E+IHC } \\
\text { only for confirmation } \\
\text { of suspicious findings }\end{array}$ & $\begin{array}{l}\text { Routine H\&E+IHC only } \\
\text { if ambiguous results }\end{array}$ \\
\hline
\end{tabular}

LNs, lymph nodes; H\&E, hematoxylin and eosin; IHC, immunohistochemistry; SLN, sentinel lymph node. 
meta-analysis ( $\mathrm{RR} 1.07 ; \mathrm{P}=0.30$ ) of the four trials reporting this data for a total of $n=5424$ patients. ${ }^{9-12}$

\section{Ipsilateral breast tumor recurrences}

Four studies reported local recurrences (ipsilateral breast tumor relapses $)^{9-12}$ for a total of $n=5424$ patients. There was no significant difference in the type of relapse between sentinel lymph node biopsy and axillary lymph node dissection (RR $1.62 ; \mathrm{P}=0.34 ; 9$ more events in sentinel lymph node biopsy arms).

\section{Loco regional recurrences (axillary and supraclavicular)}

The main concern regarding the sentinel lymph node biopsy procedure is the risk of axillary relapse. Nine more loco regional nodal relapses were recorded in the axillary lymph node dissection arms. All trials reported axillary or supraclavicular recurrences. ${ }^{9-12}$ The RR was $1.74\left(\mathrm{P}=0.13\right.$; with low heterogeneity among trials $\left[\mathrm{I}^{2} 0 \%\right]$ according to a fixed effect model; Figure 3 ). The corresponding risk difference was less than $1 \%(\mathrm{P}=0.12)$. Only three trials reported axillary and other different regional node (e.g. supraclavicular) recurrences separately so

\begin{tabular}{|c|c|c|c|c|c|c|c|c|c|}
\hline Study or Subgroup & \multicolumn{2}{|c|}{ ALND } & \multicolumn{2}{|c|}{ Control } & \multirow[t]{2}{*}{ Weight } & \multirow[t]{2}{*}{$\begin{array}{l}\text { Risk Ratio } \\
\text { M-H, Fixed, } 95 \% \text { Cl }\end{array}$} & \multirow[t]{2}{*}{ Year } & \multicolumn{2}{|c|}{$\begin{array}{l}\text { Risk Ratio } \\
\text { M-H, Fixed, } 95 \% \text { Cl }\end{array}$} \\
\hline \multicolumn{7}{|c|}{ Neg sentinel node studies } & & & \\
\hline Zavagno $2008^{12}$ & 21 & 345 & 14 & 352 & $7.6 \%$ & $1.53[0.79,2.96]$ & 2008 & & \\
\hline Canavese $2009^{\circ}$ & 5 & 110 & 4 & 115 & $2.1 \%$ & $1.31[0.36,4.74]$ & 2009 & & \\
\hline Veronesi 2010" & 15 & 259 & 23 & 257 & $12.7 \%$ & $0.65[0.35,1.21]$ & 2010 & & \\
\hline $\begin{array}{l}\text { Krag } 2010^{10} \\
\text { Subtotal }(95 \% \mathrm{Cl})\end{array}$ & 169 & $\begin{array}{l}2011 \\
2725\end{array}$ & 140 & $\begin{array}{l}1975 \\
2699\end{array}$ & $\begin{array}{r}77.6 \% \\
100.0 \%\end{array}$ & $\begin{array}{l}1.19[0.96,1.47] \\
1.15[0.95,1.39]\end{array}$ & 2010 & & \\
\hline \multicolumn{10}{|c|}{$\begin{array}{l}\text { Heterogeneity: } x^{2}=4.06, d f=3(P=0.25) ; l^{2}=26 \% \\
\text { Test for overall effect: } Z=1.40(P=0.16)\end{array}$} \\
\hline Total $(95 \% \mathrm{Cl})$ & & 2725 & & 2699 & $100.0 \%$ & $1.15[0.95,1.39]$ & & & \\
\hline Total events & 210 & & 181 & & & & & & \\
\hline \multicolumn{8}{|c|}{$\begin{array}{l}\text { Heterogeneity: } x^{2}=4.06 \text {, df }=3(P=0.25) ; l^{2}=26 \% \\
\text { Test for overall effect: } Z=1.40(P=0.16) \\
\text { Test for subaroup differences: Not applicable }\end{array}$} & $\begin{array}{l}1.50 .7 \\
\text { ALND }\end{array}$ & $\operatorname{sLNB}^{1.52}$ \\
\hline
\end{tabular}

Figure 1. Meta-analysis of overall survival of axillary lymph node dissection versus sentinel lymph node biopsy only.

\begin{tabular}{|c|c|c|c|c|c|c|c|c|}
\hline \multirow[b]{2}{*}{ Study or Subgroup } & \multicolumn{2}{|c|}{ Experimental } & \multicolumn{2}{|c|}{ Control } & \multicolumn{3}{|c|}{ Risk Ratio } & \multirow{2}{*}{$\begin{array}{c}\text { Risk Ratio } \\
\text { M-H, Fixed, } 95 \% \mathrm{Cl}\end{array}$} \\
\hline & Events & Total & Events & Total & Weight & $\mathrm{M}-\mathrm{H}$, Fixed, $95 \% \mathrm{Cl}$ & Year & \\
\hline Zavagno $2008^{12}$ & 11 & 345 & 6 & 352 & $8.4 \%$ & $1.87[0.70,5.00]$ & 2008 & \\
\hline Canavese $2009^{\circ}$ & 2 & 110 & 2 & 115 & $2.8 \%$ & $1.05[0.15,7.29]$ & 2009 & \\
\hline Veronesi 2010" & 4 & 259 & 9 & 257 & $12.8 \%$ & $0.44[0.14,1.41]$ & 2010 & \\
\hline Krag $2010^{10}$ & 56 & 2011 & 53 & 1975 & $76.0 \%$ & $1.04[0.72,1.50]$ & 2010 & \\
\hline Total $(95 \% \mathrm{Cl})$ & & 2725 & & 2699 & $100.0 \%$ & $1.03[0.75,1.43]$ & & \\
\hline Total events & 73 & & 70 & & & & & \\
\hline $\begin{array}{l}\text { Heterogeneity: } \boldsymbol{x}^{2}=3 \\
\text { Test for overall effect: }\end{array}$ & $\begin{array}{l}5, d f=3( \\
=0.19\end{array}$ & $\begin{array}{l}=0.33 \\
=0.85)\end{array}$ & $;\left.\right|^{2}=13 \%$ & & & & & 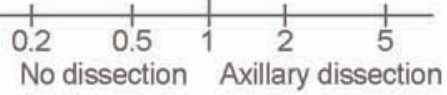 \\
\hline
\end{tabular}

Figure 2. Meta-analysis of breast cancer-specific survival of axillary lymph node dissection versus sentinel lymph node biopsy only.

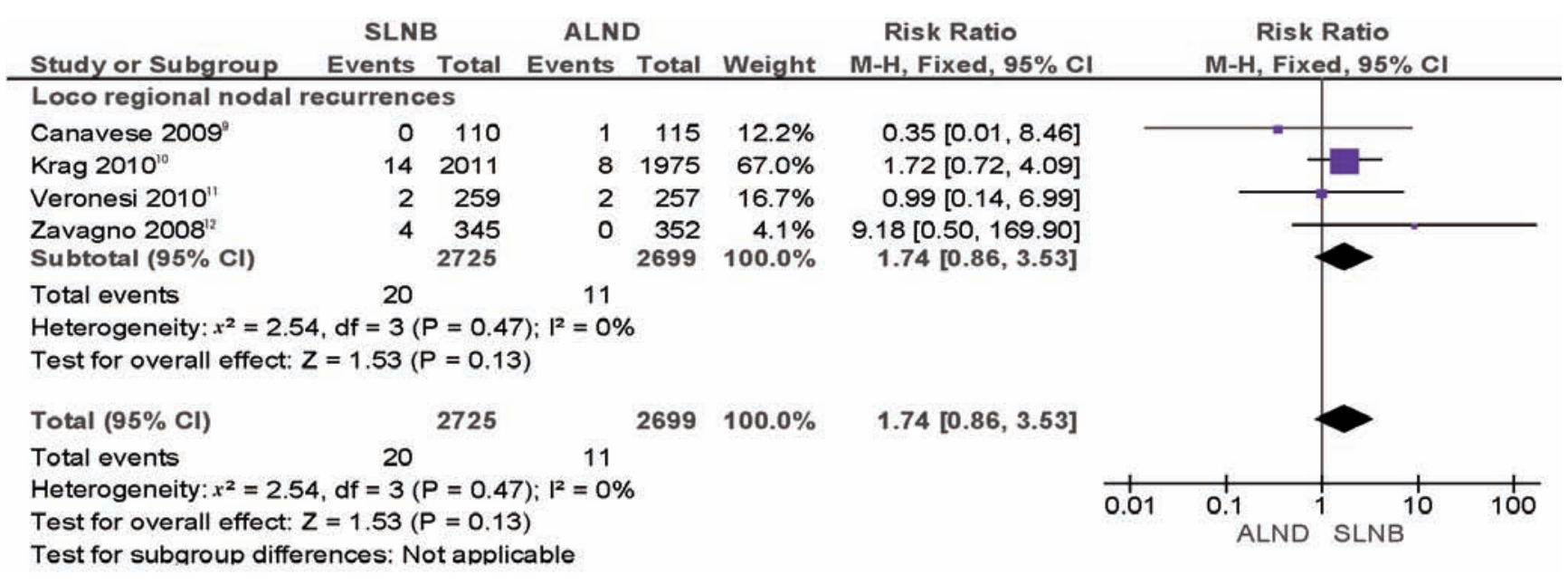

Figure 3. Meta-analysis of loco regional (axillary+supraclavicular) recurrences of axillary lymph node dissection $v s$ sentinel lymph node biopsy only. 
we decided to group nodal relapses together as loco regional recurrences, without any significant change to outcome.

\section{Distant recurrences}

Four trials reported the rate of distant metastasis. ${ }^{9-12}$ There were similar numbers of distant events in the two arms ( $\mathrm{n}=98$ and 97 in sentinel lymph node biopsy and axillary lymph node dissection trials, respectively; RR 1; $\mathrm{P}=0.98$ ).

\section{Publication bias}

Neither the Begg and Mazumdar rank correlation test $(\mathrm{P}=0.22)$ nor Egger's test $(\mathrm{P}=0.29)$ were significant. The funnel plot for analysis of loco regional recurrences is shown in Figure 4.

\section{Discussion}

The sentinel lymph node technique is based upon the observation that tumor cells migrating from a primary tumor metastasize to one or a few lymph nodes before involving other sites. These nodes (the sentinel nodes) can be identified through the injection of vital blue dye and/or radiolabeled colloid around the tumor, while their status accurately predicts that of the remaining regional lymph nodes. ${ }^{16}$ Sentinel lymph node biopsy has become the preferred nodal mapping technique for axillary staging because it has proved to be as accurate as axillary lymph node dissection with less morbidity. ${ }^{17}$

This pooled analysis compared the outcome of sentinel lymph node biopsy to that of complete axillary dissection in early stage pathologically node-negative breast cancer. Analysis confirms that clearance of the axilla is not necessary in this setting if adjuvant radiotherapy and systemic therapy are offered. In fact, survival and recurrence are not adversely affected by the omission of complete axillary staging.

The risk of a false-negative sentinel node procedure is that undiscovered, occult, positive nodes could grow into an overt clinical axillary metastasis if left untreated. However, on the basis of long-term followup studies of sentinel node mapping, this is unlikely. ${ }^{11,16}$ In our analysis the false-negative rate ranged from 2.4 to 22.9 but the RR of axillary

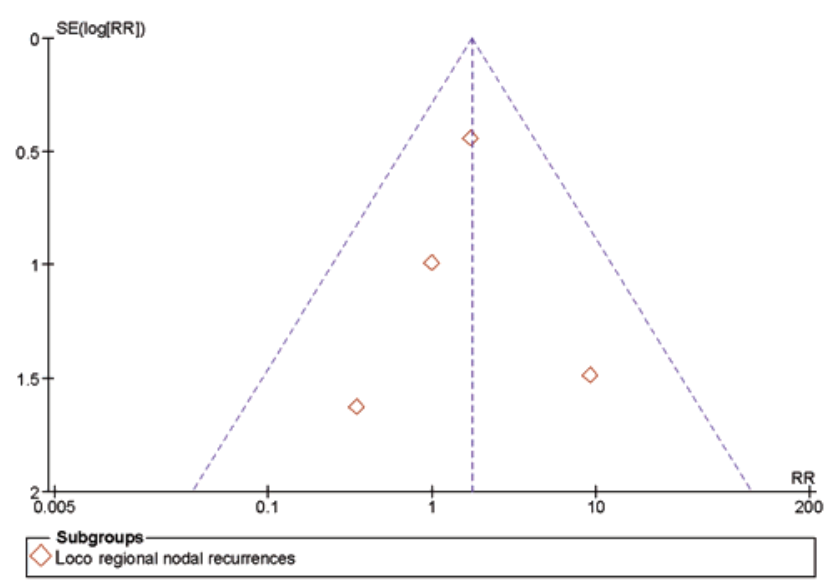

Figure 4. Funnel plot for meta-analysis of loco regional (axillary+supraclavicular) recurrences of axillary lymph node dissection versus sentinel lymph node biopsy only. recurrence (or of any loco regional nodal recurrence in the supraclavicular region) and of distant metastasis did not increase if there had been no complete axillary clearance. Also, a study with a follow-up of 56 months has reported that the oncological impact of a false negative in terms of axillary recurrences was minimal. ${ }^{18}$

The main factor underlying this result could be the low risk of relapse of these early breast cancers in the presence of both adjuvant RT and systemic therapy. Modern adjuvant therapies, both chemotherapy and hormonal therapy, are known to diminish loco regional recurrence in breast cancer patients. ${ }^{19}$ In addition, it is known that standard opposing tangential fields irradiate the sentinel lymph node operative field, much of the level I axilla, and a portion of the level II axilla. The protective role of RT was observed in the NSABP 04 trial in which randomized patients with clinically node-negative breast cancer to radical mastectomy, total mastectomy alone or in combination with RT. ${ }^{6}$ Although the 10-year survival was similar in all three groups, the axillary failure rate was significantly higher in women treated without primary axillary lymph node dissection (18\%) compared to those undergoing RT or initial axillary lymph node dissection (3.1 and 1.4\%, respectively). In the same trial, however, no patients underwent systemic adjuvant therapy that could have prevented most of the recurrences (enrollment occurred between 1971 and 1974 when no standard treatment was available). The independent and possibly additive effect of RT on medical adjuvant therapy (chemo and/or hormonal) probably leads to a reduction in the loco regional and distant failure rate, as shown in our analysis of contemporary trials on pathologically negative lymph node breast cancer. In fact, in a recent meta-analysis of the effect of RT in pN0 breast cancer after breast conserving surgery, 15year risk of death was reduced by $15 \%{ }^{20}$

One of the advantages of sentinel lymph node biopsy is that it allows the pathologist to perform a more detailed study of one or a few lymph nodes that are most likely to contain metastases, compared to lymph nodes obtained via axillary lymph node dissection. The presence of metastases that remain undiscovered using classical hematoxylin and eosin staining can be easily detected by immunohistochemical (IHC) analysis. However, the significance of these occult micrometastases is still a subject of debate. In the NSABP-B32 study, in which 3887 women underwent sentinel lymph node biopsy alone or sentinel lymph node biopsy plus axillary lymph node dissection for invasive breast cancer, micrometastases were an independent adverse prognostic factor and were associated with an increased risk of distant disease and death. ${ }^{20}$ In our analysis, all trials permitted IHC analysis of sentinel lymph nodes in cases of ambiguous or suspicious findings with classical stain. ${ }^{9-12}$ A further study that permitted hematoxylin and eosin staining only had a 1-year follow up ${ }^{13}$ but this was not long enough to discover late (occult) relapses and so was not included. The recent ACOSOG Z0010 trial confirmed the efficacy of hematoxylin and eosin staining only for the detection of micrometastases in sentinel lymph node biopsy, and the futility of IHC that does not confer prognostic significance. ${ }^{21}$ However, in light of the included trials, the double IHC plus hematoxylin and eosin staining should still be considered standard of care.

Overall, this pooled analysis shows two major outcomes for the sentinel lymph-node procedure. The first is that the survival of a patient with pathologically negative sentinel nodes is the same whether she undergoes complete axillary dissection or sentinel node mapping. In particular, the rate of loco regional failure is the same regardless of the procedure. The second and obvious conclusion is that many patients could be spared the burden of the procedures' complications, with obvious time and cost savings for the healthcare system. However, our analysis has some obvious limitations. First, potential selection bias was introduced with different inclusion criteria in the studies examined (e.g. tumor size). Second, potential operative biases were due to different follow up, different levels of surgeons' expertise, type of sur- 
gery performed and types of adjuvant therapies, despite the fact that every trial adopted a specific protocol for the selection of postoperative treatment. These factors were, therefore, not taken into consideration when performing the present meta-analysis due to the lack of individual patient data. Finally, approximately $70 \%$ of the whole weight of the meta-analysis depends on data from the NSABP B32 study. However, excluding the retrieved study with the shorter follow up (12 months), sentinel node biopsy only remains a procedure associated with similar control of disease (regional nodal relapses) and outcome (overall and breast cancer-specific survival) to that seen with complete axillary dissection in node-negative early breast cancer.

\section{Conclusions}

In summary, this review and pooled analysis of recently published randomized trials of axillary lymph node dissection treatment compared to sentinel lymph node biopsy in early (clinical node-negative) breast cancer demonstrates that axillary lymph node dissection is not associated with any survival benefit. In particular, complete axillary clearance does not appear to be justified for the prevention of axillary (and loco regional) nodal relapses nor distant metastasis. Completion of axillary lymph node dissection is not mandatory for patients with a sentinel lymph node biopsy that is negative on hematoxylin and eosin stained sections, assuming that patients will be adequately treated with whole breast radiation and some form of adjuvant systemic therapy. The overall cost and burden of toxicity associated with axillary lymph node dissection could be reduced by implementation of sentinel lymph node biopsy alone in the majority of stage I-II breast cancers; at the same time, quality of life could be improved with no adverse effect on survival.

\section{References}

1. McGee JM, Youmans R, Clingan F, et al. The value of axillary dissection in T1a breast cancer. Am J Surg 1996;172:501.

2. Fein DA, Fowble BL, Hanlon AL, et al. Identification of women with T1-T2 breast cancer at low risk of positive axillary nodes. J Surg Oncol 1997;65:34.

3. Bland KI, Scott-Conner CE, Menck H, Winchester DP. Axillary dissection in breast-conserving surgery for stage I and II breast cancer: a National Cancer Data Base study of patterns of omission and implications for survival. J Am Coll Surg 1999;188:586-96.

4. Orr RK. The impact of prophylactic axillary node dissection on breast cancer survival--a Bayesian meta-analysis. Ann Surg Oncol 1999;6:109-16.

5. Sanghani M, Balk EM, Cady B. Impact of axillary lymph node dissection on breast cancer outcome in clinically node negative patients: a systematic review and meta-analysis. Cancer 2009; 115:1613-20.

6. Fisher B, Redmond C, Fisher ER, et al. Ten-year results of a randomized clinical trial comparing radical mastectomy and total mastectomy with or without radiation. N Engl J Med 1985;312:674-81.

7. The American Society of Breast Surgeons. Guidelines for perfor- ming sentinel lymph node biopsy in breast cancer. https://www.breastsurgeons.org/statements/2010-Nov05_Guidelines_on_Performing_SLN.pdf Accessed: 23 April, 2011.

8. DerSimonian R, Laird N. Meta-analysis in clinical trials. Control Clin Trials 1986;7:177-88.

9. Canavese G, Catturich A, Vecchio C, et al. Sentinel node biopsy compared with complete axillary dissection for staging early breast cancer with clinically negative lymph nodes: results of randomized trial. Ann Oncol 2009;20:1001-7.

10. Krag DN, Anderson SJ, Julian TB, et al. Sentinel-lymph-node resection compared with conventional axillary-lymph-node dissection in clinically node-negative patients with breast cancer: overall survival findings from the NSABP B-32 randomised phase 3 trial. Lancet Oncol 2010;11:927-33.

11. Veronesi U, Viale G, Paganelli G, et al. Sentinel lymph node biopsy in breast cancer: ten-year results of a randomized controlled study. Ann Surg 2010;251:595-600.

12. Zavagno G, De Salvo GL, Scalco G, et al. A randomized clinical trial on sentinel lymph node biopsy versus axillary lymph node dissection in breast cancer: results of the Sentinella/GIVOM trial. Ann Surg 2008;247:207-13.

13. Mansel RE, Fallowfield L, Kissin M, et al. Randomized multicenter trial of sentinel node biopsy versus standard axillary treatment in operable breast cancer: the ALMANAC Trial. J Natl Cancer Inst 2006;98:599-609. Erratum in: J Natl Cancer Inst 2006;98:876.

14. Giuliano AE, McCall L, Beitsch P, et al. Locoregional recurrence after sentinel lymph node dissection with or without axillary dissection in patients with sentinel lymph node metastases: the American College of Surgeons Oncology Group Z0011 randomized trial. Ann Surg 2010;252:426-33.

15. Giuliano AE, Hunt KK, Ballman KV, et al. Axillary dissection vs. no axillary dissection in women with invasive breast cancer and sentinel node metastasis: a randomized clinical trial. JAMA 2011;305:569-75.

16. Lyman GH, Giuliano AE, Somerfield MR, et al. American Society of Clinical Oncology guideline recommendations for sentinel lymph node biopsy in early-stage breast cancer. J Clin Oncol 2005;23:7703.

17. Veronesi U, Paganelli G, Viale G, et al. A randomized comparison of sentinel-node biopsy with routine axillary dissection in breast cancer. N Engl J Med 2003;349:546-53.

18. Giuliano AE, Hawes D, Ballman KV, et al. Association of occult metastases in sentinel lymph nodes and bone marrow with survival among women with early-stage invasive breast cancer. JAMA 2011;306:385-93.

19. Buchholz TA, Tucker SL, Erwin J, et al. Impact of systemic treatment on local control for patients with lymph node-negative breast cancer treated with breast-conservation therapy. J Clin Oncol 2001;19:2240-6.

20. Darby S, McGale P, Correa C, et al. Early Breast Cancer Trialists' Collaborative Group (EBCTCG). Effect of radiotherapy after breastconserving surgery on 10-year recurrence and 15-year breast cancer death: meta-analysis of individual patient data for 10,801 women in 17 randomised trials. Lancet 2011;378:1707-16.

21. Weaver DL, Ashikaga T, Krag DN, et al. Effect of occult metastases on survival in node-negative breast cancer. N Engl J Med 2011; $364: 412-21$. 